\title{
Estado de salud bucodental de escolares residentes en localidades abastecidas con agua de consumo humano de muy alto y muy bajo contenido de fluoruros*
}

\author{
State of oral health among schoolchildren living in towns supplied with \\ drinking water containing very high and very low levels \\ of fluoride
}
Ana Isabel Azcurra, Luis José Battellino, Silvia Edith Calamari, Susana Tereza Dorronsoro de Cattoni, Mauricio Kremer, Flavia Cristina Lamberghini
Cátedra de Ouimica e Física Biologicas de la Faculdad de Odontología de la Universidad Nacional de Cordoba, Argentina (A.IA., L.J.B., S.E.C., S.T.D.C.),

Cátedra de Periodoncia de la Faculdad de Odontología de la Universidad Nacional de Córdoba - Argentina (M.K., F.C.L.)

\begin{abstract}
Se describen y analizan los resultados de una investigación epidemiológica de corte transversal destinada a evaluar el estado de salud bucodental en escolares de 6-7 y $12-13$ años residentes en Sampacho y Porteña, dos localidades de la Provincia de Córdoba (Argentina), abastecidas con agua de bebida que poseen cantldades de $F^{-}$muy diferentes. En Sampacho, el nlvel de $\mathrm{F}^{-}$es de $9,05 \mathrm{mg} / \mathrm{l}$, en tanto que en Porteña la concentración es de $0,19 \mathrm{mg} / \mathrm{l}$. La proporción de escolares (6-7 y 12-13 años) que no tuvo experiencia de caries fue significativamente mayor en Sampacho que en Porteña, mientras que los índices ceo-d, ceo-s, CPO-D y CPO-S resultaron considerablemente más altos en esta última localidad. La severidad de la enfermedad de caries en los niños de 12-13 años de Sampacho estuvo comprendida entre baja y moderada $(\mathrm{CPO}-\mathrm{D}=2,53)$, en tanto que en sus similares de Porteña alcanzó el grado de moderada a alta (CPO- $\mathrm{D}=4,41)$. No se registró ningún caso de fluorosis dental en Porteña, mientras que en Sampacho hubo una alta proporción de niños que presentó fluorosis leve (6-7 años) y leve o lntensa (12-13 años). Los niveles salivales de calcio, fosfatos, tiocianato, proteínas totales e Ig A secretoria fueron muy similares en los escolares de ambas localidades, y también entre niños con diferente experiencia de caries y distintos grados de fluorosis dental. Se concluye que son necesarias urgentes medidas sanitarias (preventivas y/o curativas) para reducir o controlar la enfermedad de caries en Porteña y la fluorosis dental en Sampacho.
\end{abstract}

Encuestas de salud bucal. Fluoración

\section{Introducción}

Desde hace unos 50 años se conoce que en los lugares donde el agua de bebida contiene concentraciones óptimas de fluoruros, la experiencia de caries dental en niños y adultos es considerable- mente menor que entre las personas residentes en zonas en las que el abastecimiento de agua de consumo humano es deficiente en esos iones ${ }^{11.38}$. En las áreas donde el contenido de fluoruros es insuficiente, la caries dental en poblaciones infantiles puede reducirse hasta un $80 \%$ mediante la fluo-

\footnotetext{
* Parte de este trabajo fue subsidiado por la Secretaría de Ciencia y Tecnología (SeCyT) de la Universidad Nacional de Córdoba Córdoba. Argentina.

Separatas/Reprints: Luis José Battellino - Cátedra de Química y Física Biológicas de la Faculdad de Odontología - Pabellon Argentina - Ciudad Universitaria (Estafeta 32) 5000 - Cordoba - Argentina

Recebido en 10.10.1994. Reapresentado en 1.8.1995. Aprobado en 7.10.1995.
} 
ruración controlada del agua (para una revisión ver $\mathrm{Keogh}^{21}$ (1972). Dado que constituye un procedimiento de fácil aplicación y la relación costo-efectividad es muy favorable, la fluoruración controlada de las aguas representa uno de los sistemas más recomendados en la prevención de la enfermedad de caries, sin riesgo para la salud general de las personas $^{21,33,45}$. La importante declinacion que en las últimas décadas ha experimentado la caries dental en la mayoría de los países industrializados es atribuible, en buena parte, a la adición de compuestos fluorados al agua de abastecimiento público hasta alcanzar concentraciones óptimas, así como también al uso extensivo de fluoruros en forma de pastas dentales, enjuagatorios, topicaciones y tabletas ${ }^{7,20}$.

El efecto cariostático de los fluoruros está relacionado con su concentración en el agua de bebida, lográndose una alta reducción en la prevalencia de caries, sin que aparezcan evidencias clínicas de fluorosis dental, con una dosis óptima de $0,7-1,2 \mathrm{mg} / 1$ (valor medio $1 \mathrm{mg} / \mathrm{l} \equiv 1$ ppm). A concentraciones del orden de $2 \mathrm{mg} / 1 \mathrm{se}$ incrementa el poder cariostático, pero entonces aparecen manchas en los dientes que constituyen el primer signo clínico del efecto tóxico del fluoruro. Se acepta que el límite de la concentración de fluoruros indispensable para producir fluoro. sis es aproximadamente el doble de la concentración óptima ${ }^{18}$.

Aunque se conoce con bastante detalle la relación entre niveles elevados de fluoruros y fluorosis dental, hay poca informacion disponible referida al efecto de sobredosis de $5 \mathrm{mg} / \mathrm{l} 6$ más sobre la caries dental. Por cuanto en la Provincia de Córdoba (Argentina) alternan zonas abastecidas con agua que poseen concentraciones óptimas $(0,7-1,2 \mathrm{mg} / \mathrm{l})$, bajas $(<0,5 \mathrm{mg} / 1)$ y altas $(>2 \mathrm{mg} / \mathrm{l})$ de $\mathrm{F}^{*}$, la misma constituye un territorio excepcional para el desarrollo de experimentos naturales sobre dicho tema.

Con el propósito de establecer el perfil epidemiológico de salud bucal en relación con la cantidad de fluoruros provistos por el agua, en 1993 fué desarrollada una investigación descriptiva sobre la población escolar de 6 y 7 y 12 y 13 años residentes en localidades con muy alto y muy bajo contenido de flúor en el agua de bebida. En el pre- sente trabajo se exponen y analizan los principales resultados de esa investigación.

\section{Material y Metodo}

\section{Población y Muestra}

La población bajo estudio comprendió todos los niños de ambos sexos, de 6, 7,12 y 13 años, concurrentes a escuelas de enseñanza primaria de la jurisdicción provincial de las localidades de Sampacho y de Porteña. Dichas localidades están ubicadas en el interior de la Provincia de Córdoba*, y son abastecidas con agua de consumo que naturalmente poseen concentraciones de $\mathrm{F}^{-}$de $9,05 \mathrm{mg} / 1$ y $0,19 \mathrm{mg} / 1$, respectivamente. En ambas localidades funcionan dos escuelas de nivel primario de la jurisdicción provincial. Por razones operativass y considerando a la escuela como unidad de muestreo, en cada localidad fue seleccionada una de ellas mediante procedimiento aleatorio simple. En base a la posición ocupacional (condición de actividad, tipo de trabajo, rama de la producción, jerarquía en el empleo) y al grado de escolaridad del principal responsable del sustento familiar, la población escolar de primer grado ( $6 \mathrm{y}$ 7 años) y séptimo grado (12 y 13 años) fue categorizada en tres niveles económicosociales (NES), denominados NES I (alto), NES II (medio) y NES $I I$ (bajo) $^{48}$. Después de estratificar las poblaciones de primer y séptimo grado por sexo y condición socioeconómica, por el procedimiento aleatorio simple se escogio en cada localidad una muestra de 100 alumnos, integrada en partes iguales por los dos grupos etáreos (6 y 7 y 12 y 13 años). La muestra final representó el $19,8 \%$ y el $21,3 \%$ de las correspondientes poblaciónes de Sampacho, y el $34,5 \%$ y el $38,5 \%$ de las de Porteña. La Tabla 1 resume la composición de la muestra.

\section{Examen Clínico Odontológico}

En el mes de octubre de 1993, los niños que integraban la muestra se sometieron a un examen clínico bucodental, el cual fue realizado en las aulas de la escuela por dos operadores previamente calibrados (FCL y MK), según el proce- 
Tabla 1. Composición de la muestra de estudio según sexo, edad y condición socioeconomica de los escolares.

\begin{tabular}{|c|c|c|c|c|}
\hline \multirow[b]{2}{*}{ Varlables } & \multicolumn{2}{|c|}{ arupo 6-7 Años" } & \multicolumn{2}{|c|}{ Grupo 12-13 Años ${ }^{* *}$} \\
\hline & $\begin{array}{l}\text { Sampacho } \\
(n=50)\end{array}$ & $\begin{array}{l}\text { Porteña } \\
(n=50)\end{array}$ & $\begin{array}{c}\text { Sampacho } \\
(n=50)\end{array}$ & $\begin{array}{l}\text { Porteña } \\
(n=50)\end{array}$ \\
\hline - Composición & $i=\begin{array}{l}48,0 \\
\{24\}\end{array}$ & $\begin{array}{l}50,0 \\
(25)\end{array}$ & $\begin{array}{l}52,0 \\
(26)\end{array}$ & $\begin{array}{l}50,0 \\
(25)\end{array}$ \\
\hline por sexo $(\%)$ & $\begin{aligned} x= & 52,0 \\
& (26)\end{aligned}$ & $\begin{array}{l}50,0 \\
(25)\end{array}$ & $\begin{array}{l}48,0 \\
\{24\}\end{array}$ & $\begin{array}{l}50,0 \\
(25)\end{array}$ \\
\hline \multirow{3}{*}{$\begin{array}{l}\text { Edad media } \\
\text { (años) }\end{array}$} & 6,4 & 6,0 & 12,3 & 12,2 \\
\hline & $\therefore=6,2$ & 6,2 & $\uparrow 2,3$ & 12,4 \\
\hline & $=6,3$ & 6.1 & 12,3 & 12,3 \\
\hline - Composición & $\begin{array}{l}8,0 \\
(4)\end{array}$ & $\begin{array}{l}8,0 \\
(4)\end{array}$ & $\begin{array}{l}6,0 \\
(3)\end{array}$ & $\begin{array}{l}6,0 \\
\text { (3) }\end{array}$ \\
\hline \multirow[t]{2}{*}{ por NES $(\%)$} & 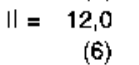 & $\begin{array}{r}18,0 \\
(9)\end{array}$ & $\begin{array}{r}12,0 \\
(6)\end{array}$ & $\begin{array}{r}14,0 \\
(7)\end{array}$ \\
\hline & $\begin{aligned} I I I= & 80,0 \\
& (40)\end{aligned}$ & $\begin{array}{r}74,0 \\
(37)\end{array}$ & $\begin{array}{c}82,0 \\
(41)\end{array}$ & $\begin{array}{l}80,0 \\
(40)\end{array}$ \\
\hline \multicolumn{5}{|c|}{$\begin{array}{l}\text { Comprende nin̂os con } 6 \text { años completos, pero que no com } \\
\text { pletaron ios } 7 \text { años. } \\
\text {.* Comprende niños con } 12 \text { años completos, pero que no } \\
\text { completaron los } 13 \text { años. } \\
\text { Los valores entre parénteses indican el número de niños } \\
\text { de cada grupo }\end{array}$} \\
\hline
\end{tabular}

dimiento de rutina tacto-visual ${ }^{\text {tho }}$, utilizando espejo, explorador y luz natural. En exámenes repetidos, las diferencias intra e interobservador no fueron estadísticamente significativas $(P<0,05)$. En cada niño se efectuó el contaje de piezas dentarias y superficies sanas, cariadas, con extracción indicada o perdidas y obturadas, en dentición temporaria y permanente, de acuerdo a los criterios propuestos por Klein et al.": A partir de esos datos se elaboraron los correspondientes índices ceo y $C P O(d$ y $s)$. Asimismo se exploró la presencia de cambios de coloración o defectos en la calcificación de los dientes, ausencia de elementos consecutivos y estado de la oclusión. El grado de fluorosis fue registrado de acuerdo a la clasificación propuesta por Dean ${ }^{12}$, estableciendo las categorías de esmalte sano, fluorosis leve y fluorosis intensa: esta última incluyó los grados de moderada y grave. El indice de salud bucal (ISB), confeccionado en base a los criterios de Koch et al..$^{23}$, permitió evaluar las condiciones generales de la boca; el valor 10 correspondió al estado de boca sana.

\section{Hábitos de Higiene Bucal y Demanda de Atención Odontológica}

Mediante encuesta por cuestionario de estructura cerrada se solicitó a los padres información respecto a la frecuencia del cepillado dental y a la periodicidad y motivo de la consulta odontológica realizada por los niños.

\section{Obtención de Saliva}

Completado el examen clínico y aproximadamente 3 horas después del desayuno, todos los niños se recogieron saliva mixta no estimulada durante $5 \mathrm{~min}$, utilizando tubos de polietileno graduados mantenidos en baño de hielo. Antes de transcurridas $2 \mathrm{~h}$, las muestras de saliva fueron centrifugadas a $4000 \mathrm{x}$ g durante $10 \mathrm{~min}, \mathrm{y}$ los sobrenadantes límpidos se congelaron a $-20^{\circ} \mathrm{C}$ para su traslado al laboratorio de Química Biológica de la Facultad de Odontología de la Universidad Nacional de Córdoba, donde las muestras se procesaron entre las 48 y $72 \mathrm{~h}$ posteriores a la recepción del material.

\section{Determinaciones Bioquímicas e Inmunológicas}

Los sobrenadantes fueron descongelados a temperatura ambiente y en ellos se realizaron determinaciones de calcio, fosfatos, tiocianato, proteínas totales e Ig A secretoria, empleando las técnicas propuestas por Bett y Frasser" Chen et al.: ${ }^{0}$, Betts y Dounton ${ }^{5}$, Lowry et al., ${ }^{-4}$, y Mancini et al., 7 , respectivamente. Las concentraciones de calcio y fosfatos se expresaron en $\mu$ moles/minuto, las de tiocianato en $\mu$ moles $/ 10 \%$ minuto y las de proteínas e Ig A secretoria en mg/minuto.

\section{Evaluación Estadística}

Según el carácter de las variables escogidas, los datos fueron evaluados estadísticamente mediante las pruebas del chi cuadrado y el análisis de varianza. El límite para establecer diferencias y asociaciones estadísticamente significativas fue fijado en $\mathrm{P}=0,05$.

\section{Resultados}

\section{Cantidad de Elementos Dentarios, Experiencia de Caries y Caries Activa}

No obstante que se demostraron diferencias inter-sexo y por la condición socioeconómica de los niños, dado que los grupos en ambas poblaciones eran totalmente semejantes, los resultados están referidos a la muestra total de cada grupo etáreo y localidad. En el grupo de 6-7 años, no hubo diferencias estadisticamente significativas entre los niños de Sampacho y Porteña en el total de dientes temporarios y/o permanentes presentes en boca al momento del examen, en la proporción 
Tabla 2. Cantidades de dientes y experiencia de caries en dentición temporaria y permanente de escolares primarios, ambos sexos, según grupo de edad y localidad de residencia.

\begin{tabular}{|c|c|c|c|c|}
\hline \multirow{2}{*}{ Dentición } & \multicolumn{2}{|c|}{ Grupo 6.7 Años } & \multicolumn{2}{|c|}{ Grupo 12-13 Años } \\
\hline & Sampacho & Porteña & Sampacho & Porteña \\
\hline $\begin{array}{l}\text { Total de dientes } \\
\text { temporarios }\end{array}$ & $16,65^{\star}$ & 16.21 & 1,28 & 0,95 \\
\hline $\begin{array}{l}\text { - Total de dientes } \\
\text { permanentes }\end{array}$ & $5,95^{*}$ & 6,30 & 25,30 & 26,00 \\
\hline $\begin{array}{l}\text { "Niños con todos los } \\
\text { caninos temporarios } \\
\text { en boca (\%) }\end{array}$ & $\begin{array}{l}98,0 \\
(49) \cdots\end{array}$ & $\begin{array}{r}100,0 \\
(50)\end{array}$ & $\cdot$ & $\cdot$ \\
\hline $\begin{array}{l}\text { Niños con todos los } \\
\text { molares temporarios } \\
\text { en boca }(\%)\end{array}$ & $\begin{array}{l}96,0 \\
48\rangle\end{array}$ & $\begin{array}{l}96,0 \\
(48)\end{array}$ & - & - \\
\hline $\begin{array}{l}\text { * Caninos temporarlos } \\
\text { erupcionados sin } \\
\text { experiencia de caries } \%\end{array}$ & 100,0 & 100,0 & $\cdot$ & . \\
\hline $\begin{array}{l}\text { "Molares temporarios } \\
\text { erupcionados sin } \\
\text { experiencia de caries(\% }\end{array}$ & $81,6^{\ldots * *}$ & 66,4 & - & $\cdot$ \\
\hline $\begin{array}{l}\text { - Niños con lodos los } \\
\text { molares permanentes } \\
\text { erupcionados }(\%)\end{array}$ & 60,0 & $\begin{array}{l}62,0 \\
(31)\end{array}$ & $\cdot$ & - \\
\hline $\begin{array}{l}\text { - Molares permanentes } \\
\text { erupcionados sin } \\
\text { experiencia de caries }(\%\end{array}$ & $95,7^{\cdots \cdots}$ & 78,1 & $51,6^{\cdots} \cdot$ & 38,3 \\
\hline $\begin{array}{l}\text { - Niños sin experiencia } \\
\text { de caries en ningün } \\
\text { diente permanente }(\%)\end{array}$ & $\begin{array}{l}90,0^{\cdots} \\
\text { b) }\end{array}$ & $\begin{array}{l}30,0 \\
(15)\end{array}$ & $\begin{array}{l}28,0^{\circ \cdots} \\
(14)\end{array}$ & $\begin{array}{l}4,0 \\
(2)\end{array}$ \\
\hline $\begin{array}{l}\text { - Los valores exp } \\
\text { temporarios o p } \\
\text { ha omitido la de } \\
* * \text { Los valores entr } \\
\text { de niños en cad } \\
* * \text { Expresa diferen } \\
\text { vas respecto a } \\
(P<0,01) \text {. Cuan } \\
\text { las diferencias } \\
\text { nificación estad }\end{array}$ & $\begin{array}{l}\text { xpresan el } \\
\text { permanen } \\
\text { desviación } \\
\text { ntre parént } \\
\text { ada grupo. } \\
\text { encias esta } \\
\text { a la poblac } \\
\text { ando no se } \\
\text { s entre los } \\
\text { distica (P. }\end{array}$ & $\begin{array}{l}\text { l promec } \\
\text { ntes, se } \\
\text { n estánd } \\
\text { tesis ino } \\
\text { adísticar } \\
\text { ción de } \\
\text { e indica } \\
\text { grupos } \\
>0,05) \text {. }\end{array}$ & $\begin{array}{l}\text { dio de dient } \\
\text { eqún el casc } \\
\text { dar. } \\
\text { dlcan el núr } \\
\text { amente sign } \\
\text { Porteña } \\
\text { an expresan } \\
\text { carecen de } \\
\text {. }\end{array}$ & $\begin{array}{l}\text { tes } \\
\text { nero } \\
\text { ificati- } \\
\text { nente, } \\
\text { e sig- }\end{array}$ \\
\hline
\end{tabular}

de escolares que conservaba la totalidad de caninos y molares deciduos, y en el número de caninos con antecedentes de caries. Lo propio ocurrió respecto a la cantidad de piezas permanentes en los grupos de 12-13 años y al porcentaje de escolares que tenían todos los molares secundarios erupcionados (Tabla 2). En cambio, en los niños de 6-7 años de Sampacho fue más alta la proporción de molares deciduos y permanentes sin experiencia de caries (diferencias del $22,9 \%$ y $22,5 \%$, respectivamente). En el grupo de 12-13 años, la diferencia se incrementó al 34,7\%. El 68,0\% de los escolares de 12-13 años de Sampacho había tenido experiencia de caries en uno o más molares permanentes, con un promedio de 2.0 molares cariados por niño. En Porteña. la proporción fue del $86,0 \%$, con un promedio de 2,5 molares permanentes cariados por niño $(\mathrm{P}<0,01)$.

En los escolares de 6-7 años, los índices ceo-d, ceo-s, CPO-D y CPO-S resultaron más bajos en la población residente en Sampacho; lo propio ocurrió con el CPO-D y el CPO-S en el grupo de 12-13 años (Figura 1). En ambos grupos etáreos, especialmente en los niños radicados en Porteña, el componente cariado fue el de mayor peso en la

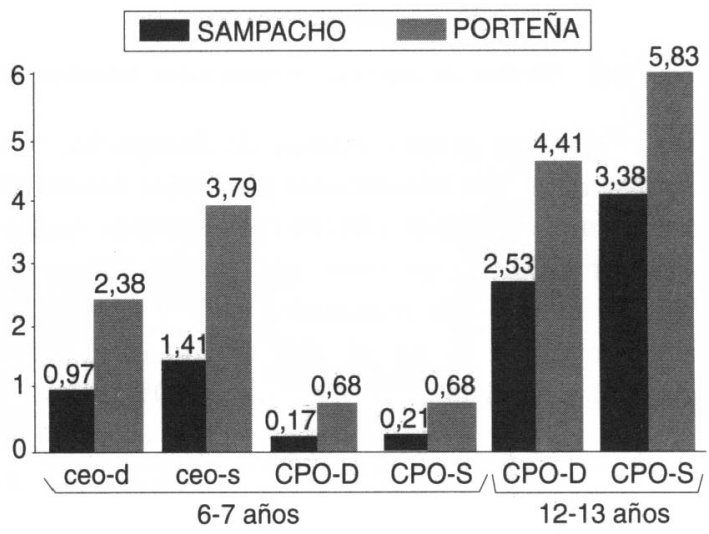

Figura 1. Indicadores de caries en niños de $6-7$ y 12 - 13 años, redidentes en Sampacho y Porteña.

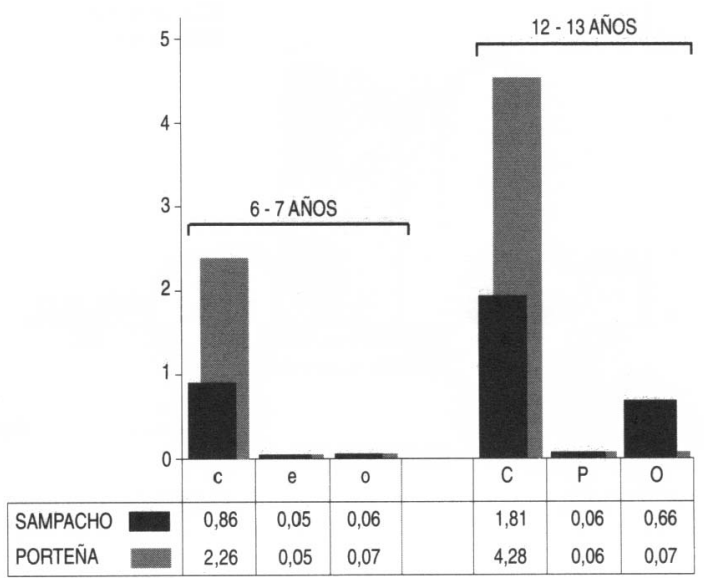

Figura 2- Dientes cariados (C), con extracción indicada (E), perdidos (P) u obturados (O) en niños de 6-7 y 12-13 años, residentes en Sampacho y Porteña.

construcción de los correspondientes índices (Figura 2). En Sampacho, la cantidad de dientes con caries activa fue $60,5 \%$ menor que en Porteña en el grupo de 6-7 años y 57,8\% a la edad de 12-13 años $(\mathrm{P}<0,01)$.

La iniciación del proceso carioso, según se infiere por el tipo de elemento y superficie dentaria que primariamente padecieron la enfermedad, fue diferente en las dos poblaciones estudia- 


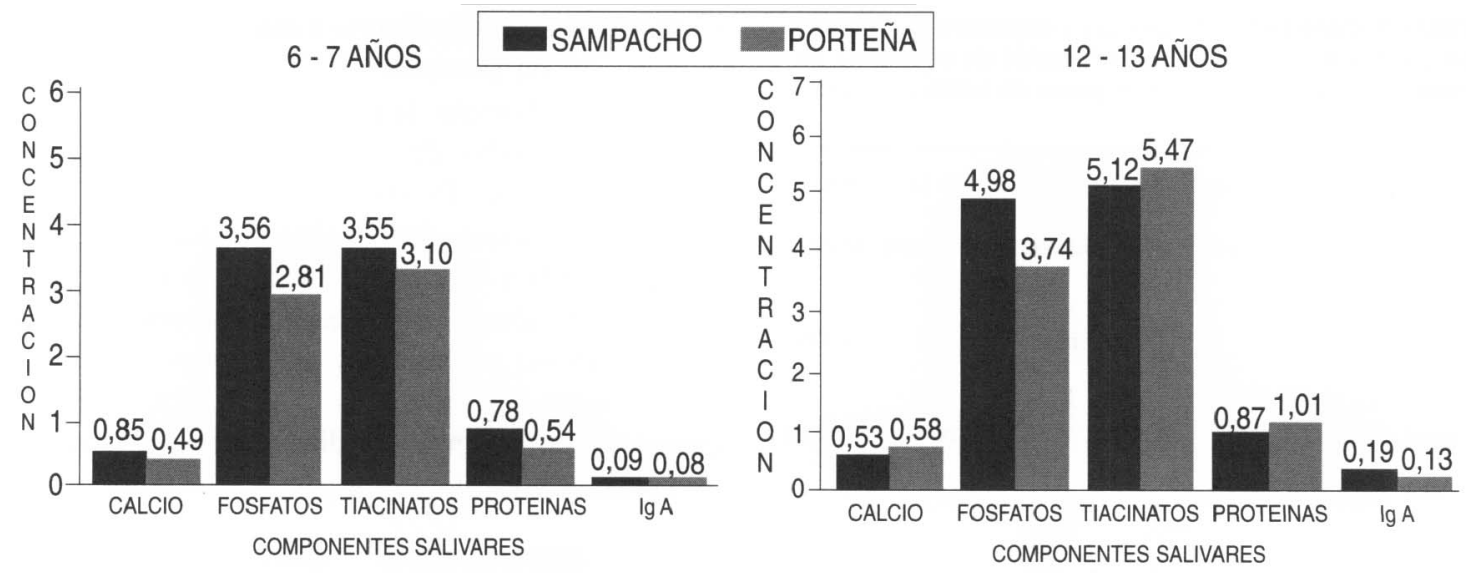

Figura 3 - Niveles de algunos componentes salivales en niños de 6-7 y $12-13$ años, según lugar de res|dencia.

das. En ambos grupos etáreos de Sampacho, los dientes afectados inicialmente por caries fueron el primer molar inferior $(80,0 \%)$ y el primer molar superior $(20,0 \%)$, en tanto que en los niños de Porteña la afección comenzó en el primer molar superior $(62,0 \%)$, en el primer molar inferior $(26,0 \%)$ y en el incisivo superior $(12,0 \%)$. En las dos denticiones de los escolares de Sampacho, la superficie oclusal fue la primera que experimentó la lesión de caries $(100,0 \%)$. Lo propio se observó en los niños de 6-7 años de Porteña $(100,0 \%)$, en tanto que en los de 12.13 años el comienzo de la caries se distribuyó entre las superficies oclusal $(68,0 \%)$ y la palatina $(32,0 \%)$.

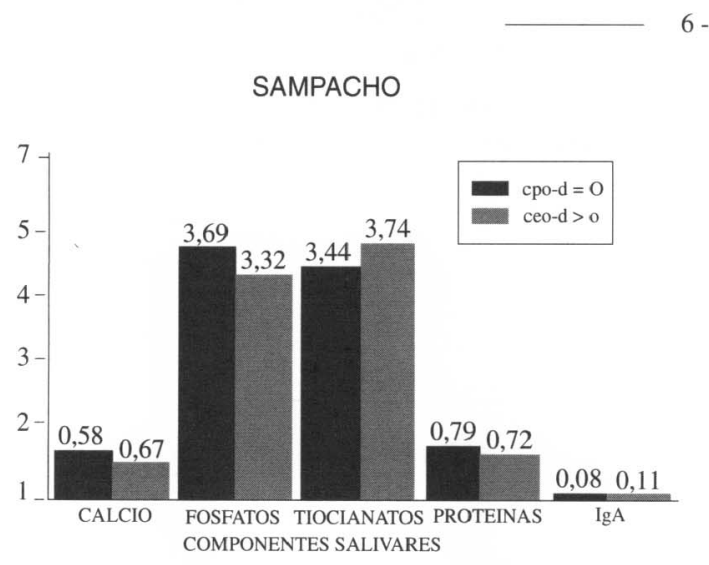

\section{6 - 7 AÑOS}

PORTEÑA

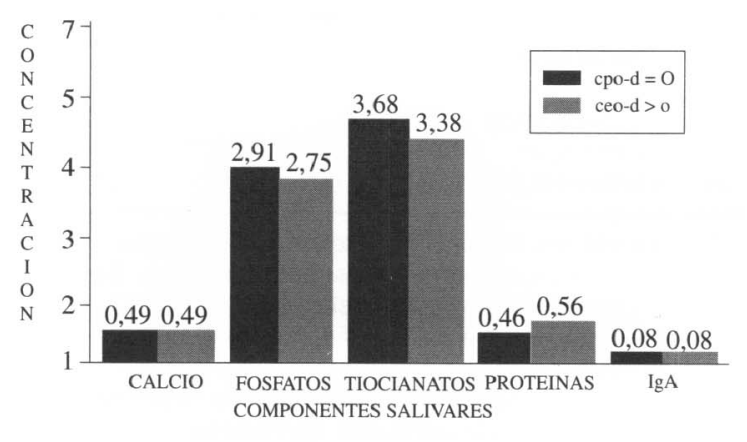

SAMPACHO

12 - 13 AÑOS

PORTEÑA
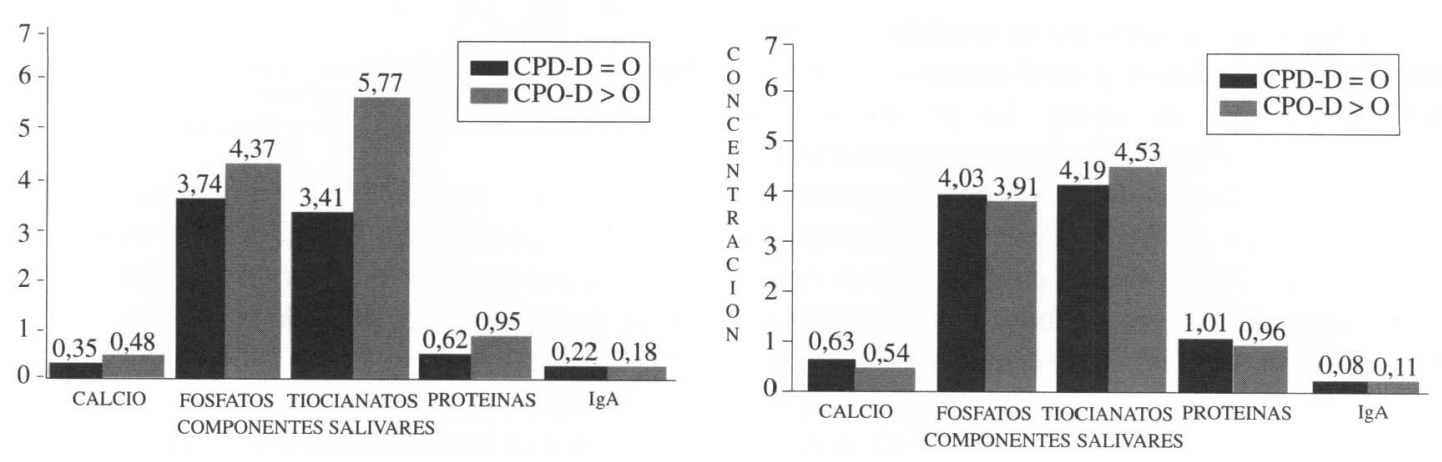

Flgura 4 - Relación entre experiencia de caries y niveles de algunos componentes salivales, según edad y lugar de residencia de los nin̄os. 


\section{Niveles de Componentes Salivales}

Según lo indica la Figura 3. la cantidad/volumen minuto de los componentes salivales cuantificados en este estudio fue muy similar entre los escolares de ambas localidades, tanto en el grupo de 6-7 años como en el de 12-13 años. no registrándose para ninguno de dichos parámetros bioquímicos diferencias estadísticamente significativas. Los niveles de todos ellos tuvieron importantes variaciones interindividuales, lo que causó marcada dispersión en los valores. También resultó muy similar en ambas poblaciones la relación molar $\mathrm{Ca} / \mathrm{P}$, que a la edad de 67 años fue 0.18 y 0.17 en Sampacho y Porteña. respectivamente, alcanzando los valores $0.11 \mathrm{y}$ 0.14 en los niños de 12-13 años. Tampoco se encontraron diferencias significativas en los niveles de dichos componentes salivales entre escolares que tuvieron experiencia de caries (ceo$d$ ó CPO-D $>0$ ) y los que nunca padecieron la enfermedad (ceo-d 6 CPO-D = 0) (Figura 4). En el grupo de 6-7 años, la relación molar $\mathrm{Ca} / \mathrm{P}$ en los niños sin experiencia de caries fue 0.16 (Sampacho) y 0.17 (Porteña), en tanto que en los que tenían antecedentes de la enfermedad fue 0.18 y 0,17 . respectivamente. Para los escolares de 12-13 años, el cociente $\mathrm{Ca} / \mathrm{P}$ alcanzó el valor 0.10 (Sampacho) y 0.16 (Porteña) en los casos en que $\mathrm{CPO}-\mathrm{D}=0$. correspondiendo una relación de 0.11 y 0.14 para los niños con CPO-D $>0$. Las diferencias en la relación $\mathrm{Ca} / \mathrm{P}$ entre los escolares de Sampacho y Porteña no alcanzaron significación estadistica. Por el contrario, el volumen minuto de saliva fue significativamente mayor en los niños de Sampacho, tanto en el grupo de 6-7 años $(0.75 \mathrm{ml}$ vs $0.53 \mathrm{ml})$ como en el de $12-13$ años $(1.04 \mathrm{ml}$ vs $0.77 \mathrm{ml})$.

\section{Higiene Dental y Experiencia de Caries}

En el grupo de 6-7 años. la proporción de niños con hábito de cepillado dental fue del $56.0 \%$ en Sampacho (38.0\% una vez y $18.0 \%$ dos o más veces diarias) y del $46,0 \%$ en Porteña ( $34.0 \%$ una vez y $12.0 \%$ dos o más veces). A los 12-13 años. el $24.0 \%$ de los niños de Sampacho realizaba cepillado dental una vez por día y el $50,0 \%$ lo hacía dos o más veces, ocurriendo lo propio en el 18,0 y $32.0 \%$, respectivamente, de los escolares de Porteña. No se comprobó correlación negativa entre la experiencia de caries y el hábito de cepillado en los niños de 6-7 años de Sampacho ni de Porteña. pero en esta última localidad la cantidad de piezas dentarias afectadas por la enfermedad disminuyó significativamente en los escolares de 12-13 años que realizaban cepillado con una frecuencia de dos o más veces diarias (Figura 5 ).

El estado general de la boca. estimado por el ISB, fue muy semejante en los niños de 6-7 años de Sampacho $(6,8)$ y de Porteña $(6,3)$. En el grupo de 12-13 años el estado de salud bucal de los escolares residentes en Sampacho fue significativamente mejor (6.8) que en los de Porteña $(4,6)$.

\section{Experiencia de Caries y Demanda de Atención Odontológica}

La demanda de asistencia odontológica fue diferente en las dos poblaciones estudiadas. La proporción de niños de 6-7 años que no recibió atención odontológica fue del $32.0 \%$ en Sampacho y del $52,0 \%$ en Porteña, en tanto que el $66,0 \%$ y el $38,0 \%$, respectivamente. asistieron para control y sólo el $2.0 \%$ y el $10.0 \%$ acudieron al profesional para recibir tratamiento restaurativo o quirúrgico. En el grupo de 12-13 años, no
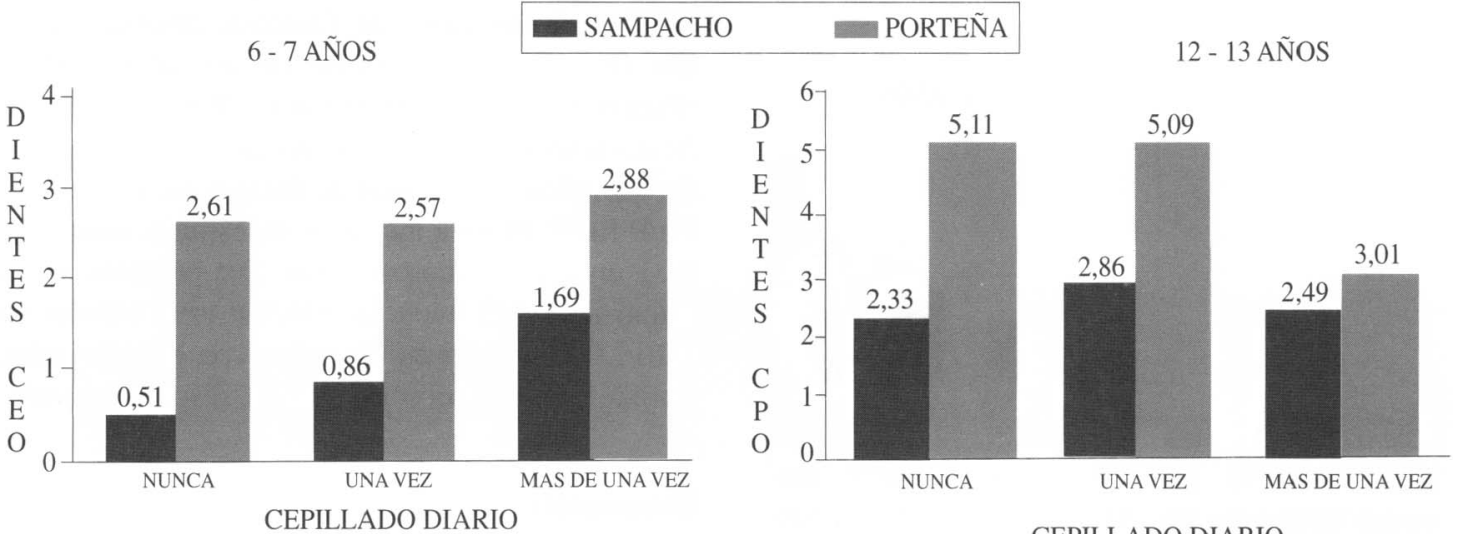

CEPILLADO DIARIO

Figura 5 - Experiencia de caries y frecuencia diaria del hábito de cepillado dental, según edad y lugar de residencia de los niños. 


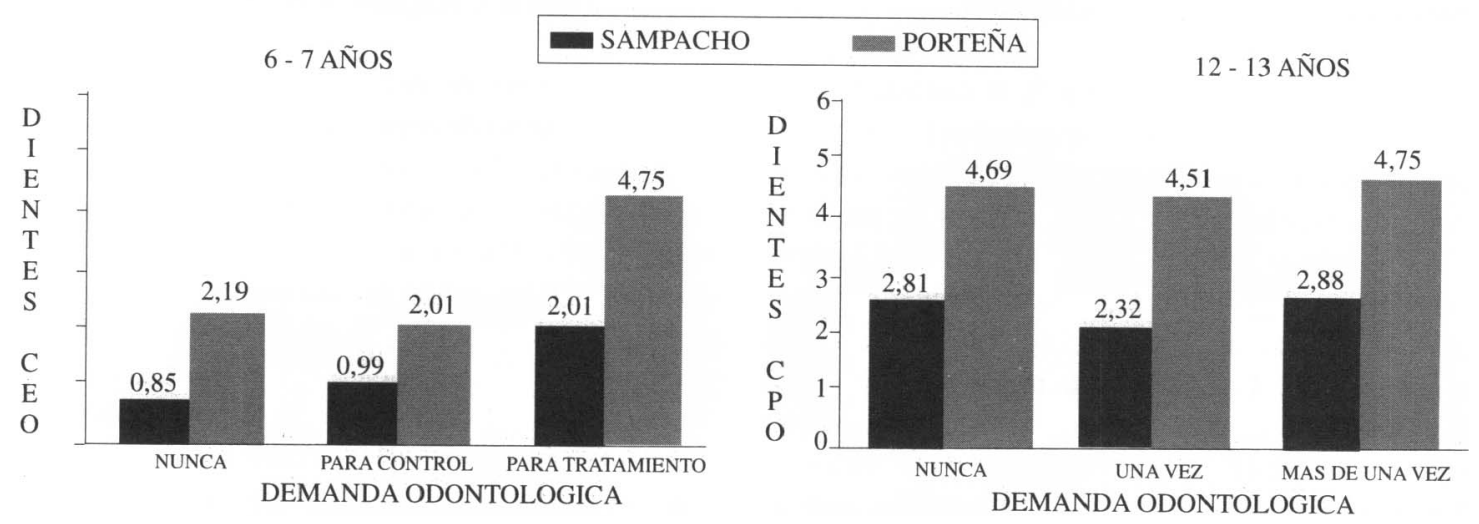

Flgura 6 - Experiencia de caries y demanda de atención odontológica, según edad y lugar de residencia de los niños.

solicitó asistencia odontológica el $16,0 \%$ en Sampacho y el $54,0 \%$ en Porteña, asistió para control el $60,0 \%$ y $26,0 \%$, y el resto $(24,0 \%$ y $20,0 \%$ ) to hizo con el propósito de lograr tratamiento odontológico. La totalidad de niños de ambas localidades que no realizaron demanda de servicios profesionales presentaban caries activas.

La Figura 6 muestra que tanto en Sampacho como en Porteña, la experiencia de caries en los dos grupos etáreos, según se infiere de los índices ceo-d
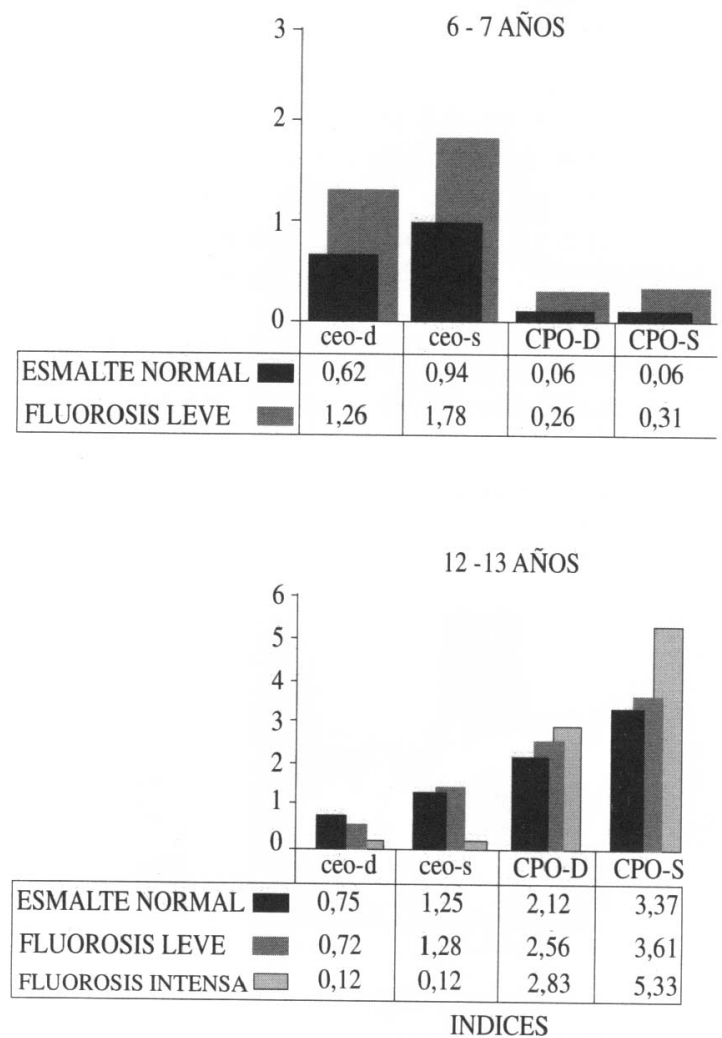

Figura 7 - Indicadores de caries y nivel de fluorosis en niños residentes en Sampacho, según edad. y CPO-D, no disminuyó por la asistencia odontológica realizada a los fines de control dental.

\section{Grados de Fluorosis, Experiencia de Caries y Componentes Salivales}

Mientras que en la población de escolares de Porteña no se registraron casos de fluorosis en ninguna de las denticiones, la mitad de los niños de 6-7 años $(52,0 \%)$ radicados en Sampacho presentó esmalte levemente moteado en los dientes deciduos, y tres de cada cuatro escolares $(78,0 \%)$ de 12-13 años mostraban dientes con diversos grados de fluorosis. La prevalencia de fluorosis leve fue aproximadamente la misma para los dos grupos etáreos, resultando mucho más frecuente el estadio moderado y grave (fluorosis intensa) en el grupo de 12-13 años. Los indicadores de caries aumentaron a medida que fue mayor la severidad del moteado, siendo el componente cariado el principal responsable de este aumento (Figura 7). No se registraron diferencias estadísticamente significativas en los niveles de los componentes salivales estudiados de acuerdo al grado de fluorosis, excepto en los casos de fluorosis intensa, en los que fue mayor la cantidad de tiocianato/minuto (Figura 8). La relación molar $\mathrm{Ca} / \mathrm{P}$ no varió significativamente según la severidad de la fluorosis. En los niños de 6-7 años de Sampacho, el cociente $\mathrm{Ca} / \mathrm{P}$ fue 0,18 para los casos de esmalte sano y de 0,21 en los de fluorosis leve. Por su parte, en el grupo de 12-13 años, la relación tuvo valores de $0,10,0,11$ y 0,08 en los nir̃os con esmalte sano, fluorosis leve y fluorosis intensa, respectivamente.

\section{Discuslón}

Los resultados de la presente investigacion, de acuerdo a lo que evidencian los índices ceo-d, ceo- 

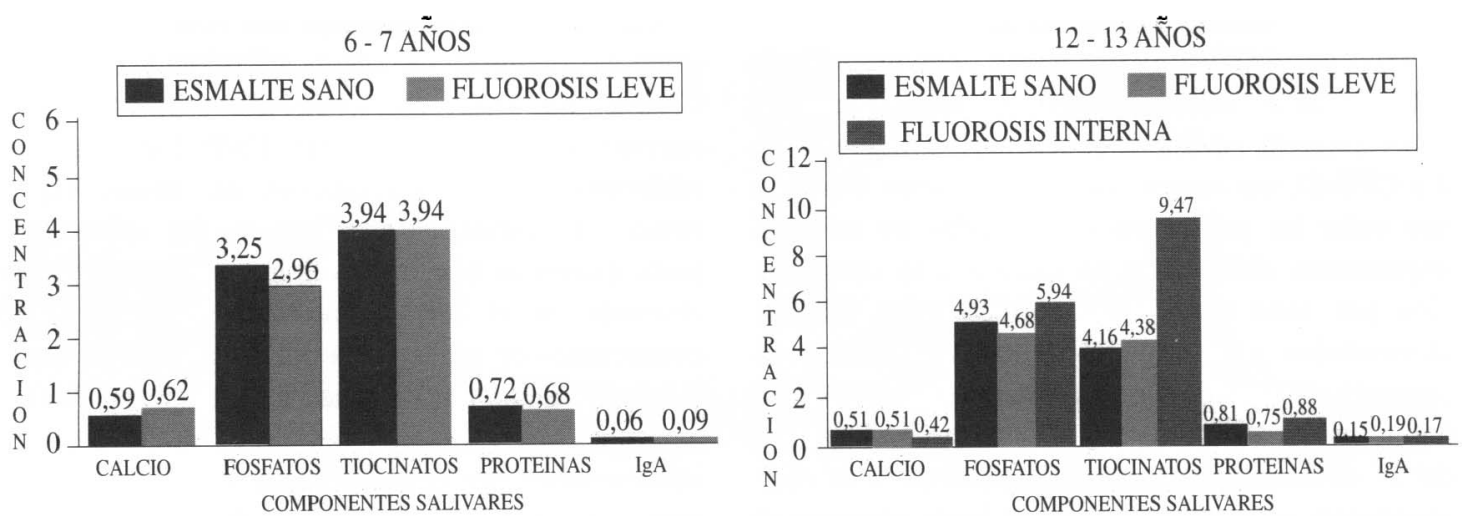

Figura $\mathbf{B}$ - Relación entre grado de fluorosis y niveles de algunos componentes salivales en nif́os residentes en Sampacho, según edad.

s, CPO-D y CPO-S, revelan que en los escolares de 6-7 y 12.13 ajios residentes en Sampacho, donde el nivel de F- del agua de consumo humano es de $9,05 \mathrm{mg} / \mathrm{l}$, la prevalencia de caries en dentición primaria y secundaria fue menor que en sus similares de Porteña, localidad en la que el abastecimiento de agua es de muy bajo contenido en fluoruros $(0,19 \mathrm{mg} / 1)$. Además, el estado de salud bucodental, de acuerdo al ISB, es mejor en los niños de Sampacho que en los de Porteña.

Estos resultados son coincidentes con los que informa la literatura intemacional respecto a la diferente experiencia de caries que tienen las comunidades en las que el agua de consumo humano posee concentraciones óptimas (o mayores) de $\mathrm{F}^{-}$y las que tienen niveles deficientes de dicho ion , $^{8,11,21.25 .32 .38}$.

Si se adoptar el criterio propuesto por Sicilia ${ }^{41}$ de categorizar la severidad de caries de acuerdo al valor del CPO-D, se pode afirmar que en el grupo de escolares de 12-13 años residentes en Sampacho (CPO-D $=2,53$ ) la prevalencia de dicha enfermedad está ubicada entre baja y moderada $(1,2-2,6$ y $2,7-4,4$, respectivamente) y que se habría alcanzado una de las metas fijadas por la OMS para el año 2000 , esto es, lograr que a esa edad los niños tengan menos de tres dientes cariados, perdidos $u$ obturados $^{14}$. En cambio, para ese grupo etario de Porteña, el valor CPO-D ${ }^{4,41}$ corresponde a las categorías moderada a alta $(2,7-4,4$ y $4,5-6,5$, respectivamente). La elevada frecuencia de caries en la dentición permanente de esta población resulta justificada, habida cuenta que una alta proporción de sus dientes temporarios tuvieron experiencia de caries y que no se aplicaron políticas sanitarias integrales tendientes a erradicar o reducir la enfer. medad $^{19,42}$.

Por cuanto los niños de Sampacho recibieron desde el nacimiento cantidades de fluoruros que satisfacen ampliamente sus necesidades, la dentición se ha visto favorecida tanto en la etapa preeruptiva (fases de mineralización y postmineralización) como en la posteruptiva, y a consecuencia de ello se formó un tejido adamantino especialmente enriquecido en $\mathrm{F}^{-}$en las capas superficiales e inmediatamente debajo de ellas, que son precisamente las zonas donde se inicia el proceso carioso. Asimismo, el $\mathrm{F}^{-}$pudo incorporarse al esmalte en la etapa posteruptiva, durante el proceso de maduración, o bien remineralizando el tejido que ha sido parciaimente desmineralizado ${ }^{13}$. Además, los iones fluoruro completan su efecto cariostático afectando la composición bacteriana de la placa dental y con ello la producción de ácidos por parte de los gérmenes odontopáticos ${ }^{1,17.21}$.

Por su morfología y erupción temprana, Jos molares permanentes son generalmente las piezas dentarias más afectadas en los primeros años de vida. La ingestión de $\mathrm{F}^{*}$ mediante el agua de bebida produce una selectiva protección de las zonas proximales de esos dientes, zonas que resultan de difícil acceso para la limpieza mecánica por parte de la sailiva y del cepillado dental, aunque no ocurren modificaciones importantes en ja anatomía oclusal de los molares deciduos y permanentes ${ }^{16}$. En correspondencia con ello, encontrase que los escolares de Sampacho tuvieron una experiencia de caries en molares significativamente más baja que los de Porteña, y que en ambos grupos etáreos de aquella localidad el proceso carioso se inicia exclusivamente en las superficies oclusales de dichos elementos dentarios.

Pese a que el estado de salud bucodental de los niños de Sampacho supera a los de Porteña, no puede decirse que hayan logrado el nivel ideal. En un estudio realizado por Yankilevich \& Battelli$n \mathrm{no}^{47}$ sobre una muestra muy grande de escolares de 
6-7 y 12-13 años de la Ciudad de Córdoba. donde el agua de abastecimiento posee concentraciones óptimas de $\mathrm{F}^{-}(0.8-1.0 \mathrm{mg} / \mathrm{l})$ se encontró que la experiencia de caries, de acuerdo a los índices ceod y CPO-D, era menor que en Sampacho. Por esto que entre las poblaciones estudiadas no existían importantes diferencias en cuanto a la composición por sexo y nivel económicosocial, hábitos alimentarios y de higiene dental y demanda de atención odontológica, las diferencias probablemente deben atribuirse a que el efecto cariostático del $\mathrm{F}^{-}$se incrementa proporcionalmente a su concentración en el agua de bebida hasta alcanzar el máximo cuando los niveles superan en tres veces la concentración óptima ${ }^{13}$. Concentraciones más altas de $\mathrm{F}^{-}$. en tanto acentúan la severidad de la fluorosis, provocan la ruptura de la integridad del esmalte al interrumpir el depósito de matriz orgánica e inducir la deposición irregular del material mineral, haciendo que el tejido resulte más vulnerable a la caries ${ }^{21}$.

Aunque la composición salival se menciona como un factor esencial en el mantenimiento de la salud bucal. los resultados de esta investigación no demostraron asociación entre la resistencia a la caries y el contenido de ciertos componentes normales de la saliva, en coincidencia con las conclusiones de investigaciones previas realizadas por otros autores ${ }^{3 ! 19}$. Por cuanto la progresión de la caries es discontinua, esta aparente contradicción puede atribuirse. al menos en parte. al hecho de que el valor de los índices ceo y CPO y el de cada uno de sus componentes, a partir de los cuales se infiere la experiencia de enfermedad dental. son una expresión de eventos que ocurrieron en el pasado. los que no necesariamente se corresponden con la composición de la saliva al momento de realizar la investigación.

El contenido salival de calcio y fosfato y la relación molar entre ambas especies iónicas en los escolares de Sampacho fue cási idéntico al de los niños de Porteña, pese a existir una importante diferencia en la experiencia de caries entre ambas poblaciones. Este hallazgo es concordante con los resultados obtenidos por $\mathrm{Mandel}^{29}$, quien demostró que los niveles de calcio en saliva son muy similares entre individuos sensibles y resistentes a la caries. En contraposición a ello, otros investigadores han comunicado modificaciones en la concentración de calcio y fosfato salival en relación con Ia experiencia de caries. Maijer y Classen ${ }^{23}$ y Turtola $a^{4.2}$ hallaron que la concentración de calcio en saliva se incrementa con la frecuencia de caries, en tanto que Ashley ${ }^{2 . ;}$, Shannon y Feller ${ }^{30}$ y Shaw et al. ${ }^{2}$ comunicaron una relación inversa entre el contenido de calcio y fosfato y el índice CPO-S. En niños de 13-15 años. Shaw et alt? encontraron que el cociente $\mathrm{Ca} / \mathrm{P}$ fue considerablemente mayor en quienes no tenían experiencia de caries. Por cuanto en los niños que participaron en nuestra investigación la saliva fue obtenida en el mismo momento del día. bajo condiciones de reposo y la concentración de $\mathrm{Ca}$ y $P$ fue expresada por volumen minuto, se pode afirmar que los resultados obtenidos no estuvieron influenciados por el tipo y duración del estímulo. ritmo circadiano y velocidad de flujo salival ${ }^{1: 2 ?}$.

No obstante que ciertas proteínas salivales están relacionadas con la formación de la película adquirida y de la placa bacteriana, y en consecuencia serían predecibles niveles más bajos en individuos con mayor experiencia de caries ${ }^{\psi}$. el hecho de que la saliva contenga más de 200 variedades distintas de estas macromoléculas". podría ser la causa de no haber encontrado diferencias significativas en la cantidad de proteinas to-tales entre los escolares de Sampacho y Porteña.

Al igual que en esta investigación. Lambert et al. ${ }^{i+}$ no hallaron diferencias estadísticamente significativas en la concentración de tiocianato entre jóvenes con diferente experiencia de caries dental. pese a que dicho ión integra el sistema de peroxidasa salival, uno de los factores con actividad antimicrobiana frente a los gérmenes cariógenos. Del mismo modo, la similitud en la concentración de Ig A secretoria total en los niños de Sampacho y Porteña, coincide con comunicaciones de otras investigaciones en las que no pudo demostrarse asociación entre la frecuencia de caries y este isotipo de inmunoglobulinas

Se conoce en la actualidad que el contenido de $\mathrm{F}^{-}$en saliva es proporcional a su concentración en sangre y ésta. a su vez. depende del tenor de dicho ión en el agua de bebida*. La cantidad de $\mathrm{F}^{-}$que se excreta en la saliva se correlaciona positivamente con la velocidad de flujo:i. El esmalte y la dentina. la placa bacteriana y los tejidos blandos constituyen los reservorios de $\mathrm{F}^{-}$en la cavidad bucal. A nivel del esmalte. el $\mathrm{F}^{-}$proveniente de la saliva queda retenido uniéndose con $\mathrm{Ca}^{-+}$, formando transitoriamente un precursor de la fluorapatita $\left(\mathrm{CaF}_{2}\right)$ muy poco soluble en saliva a $\mathrm{pH}$ neutro, en la superficie de cuyos cristales pueden adsorberse el fosfato secundario " o proteínas. En consecuencia. en los niños de Sampacho. donde son muy altos la velocidad de flujo salival y el consumo de $\mathrm{F}^{-}$por el agua de bebida, se esperaba encontrar que 
la concentración de calcio y/o la relación molar $\mathrm{Ca} / \mathrm{P}$ estuvieran modificadas correlativamente con la severidad de la fluorosis. En verdad, no se pudo demostrar ninguna variación importante, y dado la complejidad de factores que mantienen el equilibrio iónico en se saliva, se carece de una explicación lógica de esta aparente contradicción.

En conciusión, los resultados de esta investigación indican que existe una desigual distribución de la enfermedad de caries entre localidades

\section{Referências Blbliográficas}

1. AMERICAN DENTAL ASSOCIATION: Fluoridation facts. Chicago, 1989.

2. ASHLEY, F.P. The relationship between diet, saliva, plaque and caries. J. Dent. Res.; 51: 1234,1972 .

3. ASHLEY, F.P. Calcium and phosphorus concentration of dental plaque related to dental caries in 11-to 14-year-old male subjects. Caries Res., 9: 351-62, 1975.

4. BETT, J.M. \& FRASER, J.P. A rapid micromethod for determination serum calcium. Biocbem. $J$, 68: 13,1958 .

5. BETTS, R.H. \& DOUNTON, F.S. Electron transfer and other processes involved in the spontaneous bleaching of acidified aqueous solutions of ferric thiocyanate. Am. Cbem. Soc., 75: 5721-7,1953.

6. BRLLN, C. \& THYLSTRLP, A. Fluoride in whole saliva and dental caries experience in areas with high or low concentration of fluoride in the drinking water. Caries Res.; 18: 450-6, 1984.

7. BURT, B.A. The changing patterns of systemic fluoride intake. J. Dent. Res., 71: 1228-37, 1992.

8. CARMICHAEL, C.L. The relationship between fluoridation, social class, and caries in 5 year old of children Newcastle and Northumberland in 1987. Br. Dent. J, 167: 57-61, 1989.

9. COWMAN, R.A. et al. Differential utilization of protein in saliva from caries-active and cariesfree subjects as growth substrates by plaqueforming streptococci. J. Dent. Res., 58: 201927, 1979.

10. CHEN, P.S. et al. Microdetermination of phosphorus. Anal. Chem., 28: 1756-8, 1956.

11. DEAN, H.T. et al. Domestic water and dental caries. Public Health Rep., 57: 1155-61, 1942.

12. DEAN, H.T. Classification of mottled enamel diagnosis. JADA, 21: 1421-6, 1934

13. DRISCOLL, W.S. et al. Prevalence of dental caries and dental fluorosis in areas with optimal and above-optimal water fluoride concentrations, JADA, 107: 42-7, 1983.

14. FDI/OMS. Patrones cambiantes de salud bucodental e implicaciones para los recursos con abastecimiento de agua conteniendo cantidades mínimas de $\mathrm{F}^{-}$y otras que poseen una sobredosis de dichos iones, con predominio en las poblaciones que residen en aquéllas. En las últimas, si bien la caries no ha desaparecido, la afección que merece mayor atención es la fluorosis dental. Para ambas enfermedades, existen medidas preventivas y curativas que son muy accesibles, y cuya aplicación permitirá mejorar el estado de salud bucodental de las respectivas comunidades .

humanos dentales. Arcb. Odontoestomatol, 2: $23-40,1986$.

15. FERGUSON, D. \& BOTCHWAY, C.A. Circadian variations in the flow rate and composition of whole saliva stimulated by mastication. $A r c b$. Oral Biol., 24: 877-81, 1980.

16. FOREMAN, F.J. \& RETZLAFF, A.E. Effects of systemic fluoride on the morphology of occlusal grooves of primary and permanent molars, $J$. Dent. Cbild., $57: 101-5,1990$.

17. GREMBOWSKI, D. et al. How fluoridation affects adult dental caries. JADA, 123: 49-54, 1992.

18. HEIFETZ, S.B. Prevalence of dental caries and dental fluorosis in areas with optimal and above optimal water fluoride concentrations: a 5 year-follow-up survey, JADA, 116: 490-5, 1988.

19. HELM, S. \& HELM, T. Correlation between caries experience in primary and permanent dentition in birth-cohort 1950-1970. Scand. J. Dent. Res., 98: 225-7, 1990.

20. KALSBEEK, H. \& VERRIPS, G.H.W. Dental caries prevalence and the use of fluorides in different European countries. J. Dent. Res., 69 (Sp Iss): $728-32,1990$.

21. KEOGH, T,P. Fluoración de las aguas de consumo humano: Controversia o ilusión? Acta Odontoestomatol. Española, 417: 37-58, 1992.

22. KLEIN, H. et al. Studies on dental caries.I. Dental status and dental needs of elementary school children. Public Health Rep., 53: 751-65, 1938.

23. KOCH, A.L. et al. A children s oral status index based on dentist judgment. JADA, 110: 36-42, 1985.

24. LAMBERTS, B.L.et al. Comparison of salivary peroxidase system in caries-free and cariesactive naval recruits. Caries Res., 18: 48894,1984.

25. LEMANSEY, J.F. Effects of fluoridation on dental health in 5 and 11 year old irish schoolchildren. Comm. Dent, Oral Epidemiol, 12: 21822, 1984 .

26. LOWRY, O.H, et al. Protein measurement with the folin phenol reagent. J. Biol. Cbem., 193: 265-75, 1951

27. MANCINI, G., et al. Immunochemical quantitation of antigens by single radical immunodiffusion. Immunocbemistry, 2: 235-7, 1965. 
28. MAIJER, R, \& CLASSEN, G.A. Ionized calcium concentration in saliva and its relationship to dental disease. J. Can. Dent. Ass., 9: 333-6, 1972.

29 MANDEL, I.D. Relation of saliva and plaque to caries, J. Dent. Res., 53 (Suppl 2): 246-71, 1974.

30 MANDEL, I.D. \& BENNICK, A. Quantitation of salivary acidic proline-rich phosphoproteins in oral disease. AADR Prog E Abst., 59: 909, 1980.

31. MARSHALL, T. Protein heterogeneity in human saliva. Electropboresis, 5: 245-50, 1984.

32. MITROPOLUS, C.M. et al. Differences in dental caries experience in 14 year old children in fluoridated South Birminghan and in Bolton in 1987. Br. Dent. J., 164: 349-50, 1988.

33. NEWBRLN, E. Presenting dental caries: current and prospective strategies. $J A D A, 123: 68-73$, 1992.

34. OLIVEBY, A. et al. Studies on fluoride excretion in human whole saliva and its relation to flow rate and plasma fluoride levels. Caries Res., 23: $243-6,1989$.

35. ROLLA, G. \& OGAARD, B. Studies on the solubility of calcium fluoride in human saliva. In: Leach, S. A. ed. Factors relating to demineralisation of teetb. Oxford, IRI Press Ltd, p. 45-50, 1986.

36. ROLIA, G. \& SAXEGAARD, E. Critical evaluation of the composition and use of topical fluoricles with emphasis on the role of calcium fluoride in caries inhibition. J. Dent. Res, 69 (Sp Iss): 780-5, 1990.

37. RUDNEY J.D. Correlations between human salivary levels of lysozyme, lactoferrin, salivary peroxidase and secretory immunoglobulin A with stimulatory states and over time. Arch. Oral. Biol., 30: 765-71, 1985.

38. RLSSEL, A.L. \& ELVOLVE, E. Domestic water and dental caries. VII. A study of the fluoridedental caries relationship in adult population. Public Health. Rep., 66: 1389-97, 1951.

39. SHAN_NON, I.L. \& FELLER, R.P. Parotid saliva flow rate, calcium, phosphorus, and magne- sium concentrations in relation to dental caries experience in children. Pediat. Dent., 1: $16-20,1979$.

40) SHAW, L. et al. Calcium and phosphorus content of plaque and saliva in relation to dental caries. Cartes Res, 17: 543-548, 1983.

41. SICILIA, A. Prevalencia de caries en los niños y jóvenes espanoles de siete, doce y quince a diecinueve años. Avanc. Odontoestomatol, 6: 323-30, 1990.

42. TER PELKWLK, L. et al. Caries experiencie in the deciduous dentition as predictor for the caries in the permanent dentition. Caries Res., 24: 65-71, 1990 .

43. TURTOLA, L.O. Salivary fluoride and calcium concentrations and their relationship to the secretion of saliva and caries experience. Scand. J. Dent. Res, 85: 535-41, 1977.

44. TWETMAN, S. Lysozyme and salivary immunoglobulin A in caries-free and caries-susceptible preschool children. Sued Dent. J., 5: 9 14,1981

45. UNITED STATES PUBLIC HEALTH SERVICES. Department of Health and Human Services. Review of fluoride benefits and risk: report of the ad boc Subcommittee on Fluoride of the committee to coordinate environmental bealtb and related programs. Bethesda, 1991.

46. WORLD HEAITH ORGANIZATION. Oral bealth surveys, basic metbods. 2nd ed. Geneva, 1977.

47. YANKILEVICH, E.R.L.M. de \& BATTELLINO, I.J Prevalencia de la caries dental en escolares de nivel primario de una región metropolitana de la provincia de Córdoba, Argentina. Rev. Satide Püblica., 26: 210-23, 1992.

48. YANKILEVICH, E,R.L.M. et al. Distribución de la caries dental en niños preescolares en una región urbana, Argentina, 1992. Rev. Saúde Püblica., 27: 436-44, 1993.

49. ZWNGO, A.N. et al. Salivary studies in human caries resistance. Arch. Oral Biol, 16: $557-60$, 1971. 


\section{Abstract}

The resuits of a cross sectional epidemiological survey for the purpose of evaluating the state of dental health of schoolchildren (aged 6-7 and 12-13) living in Sampacho and Porteria, two towns in the Province of Cordoba (Argentina), supplied with drinking water containing quite different levels of fluoride, are described and analized. in Sampacho, Flevel is $9.05 \mathrm{mg} /$. While in Portena the concentration is of $0.19 \mathrm{mg} /$. The proportion of scholchildren (aged 6-7 and 12-13) without caries was significaticantly higher in Sampacho than in Porteria, while the dmi-t, dmf-s, DMF-T and DMF-S indexes were considerably higher in the latter place. The severity of caries in children (age 12-13) iving in Sampacho ranged from low to moderate (DMF- $T=2.53$ ), whilst in Portena the range went from moderate to high (DMF-T=4.41). No cases of dental fluorosis were recorded in Porteña; but in Sampacho, there was a high propontion of children with mild flworosis (aged 6-7) and mild or severe ftuorosis (aged 12-13). Catcium, phosphate, thiocyanate, protein and secretory ig A salivary levels were similar not only among schoolchildren of both towns but aiso among those with different experience of caries and different degrees of severity of fluorosis. It is concluded that urgent (preventive and/or curative) sanitary measures are necessary for the purpose of reducing or controlling caries in Porteña as well as dental fluorosis in Sampacho.

Dental health.surveys. Fluoridation,

\section{Resumo}

Descrevem-se e analizam-se os resultados de uma pesquisa epidemiológica de corte transversal destinada a avaliar o estado de saude buco-dental de escolares de 6-7 e 12-13 anos, residentes em Sampacho e Porteña, duas localidades da Provincia de Cordoba (Argentina), abastecidas com água potável contendo quantidade de $F$ muito diferentes. Em Sampacho o nivel de $F$ é de $9,05 \mathrm{mg} / \mathrm{l}$ enquanto que em Porteña a concentração é de $0,19 \mathrm{mg} /$. A proporção de escolares (6-7 e $12-13$ anos) que nảo apresentaram cárie foi significativamente maior em Sampacho do que em Portenta, enquanto, que os indices ceo-d, ceo-s, CPO-D e CPO-S resultaram consideravelmente mais altos nesta uitima localidade. A severidade da doença de cárie nas crianças de $12-13$ anos de Sampacho esteve compreendida entre as categorias baixa e moderada ( $C P O-D=2,53)$, enquanto que em suas similares em Porteña atingiu o grau de moderada $\theta$ aita (CPO-D=4,41). Nâo se registrou nenhum caso de fiuorose dental em Porteña enquanto que em Sampacho houve uma alta proporçäo de crianças que apresentou fluoroses leve (6-7 anos) e leve ou intensa (12-13 anos). Os niveis salivares de cálcio, fosfatos, tiocianato, proteinas totais e ig $A$ secretora foram muito similares nos escolares de ambas localidades, $e$ também entre crianças com diferentes tipos de cárie e diferentes graus de gravidade de fluorose. Conciui-se ser necessária a aplicação de medidas sanitárias urgentes (preventivas ou curativas) para reduzir ou conirolar as doenças de cárie em Porteña e a fluorose dental em Sampacho.

Levantamentos de sáde bucal. Fluoretação. Cárie dentária, epidemiologia. 